\title{
Effects on environmental conditions of constructing a u-turn in East Tehran Highway
}

\author{
S. Boudaghpour \& A. R. Jadidi \\ Civil Engineering Department, Islamic Azad University South Branch, \\ Tehran, Iran
}

\begin{abstract}
One of the main important highways that connects the north-east to the south, and the south part of Tehran, is the Afsariyeh highway. It acts as a powerful tool to transport approximately 150000 heavy and light vehicles daily. Owing to Iran's regulations, it is not possible to construct a crossing on such highways. Therefore, construction of a u-turn in highways can be the best decision to accelerate traffic movement, while increasing the safety of vehicles and decreasing the vehicle movement's lag time. All these factors cause a heavy reduction of air and sound pollution. In the present research the number of daily vehicles before and after the u-turn construction, the percentage reduction of vehicle lag time and the considerable reduction of air and pollution have been studied.
\end{abstract}

Keywords: u-turn, air pollution, environment, heavy traffic.

\section{Introduction}

Daily development and expansion of cities are a global phenomena and Tehran is no exception. Irregular expansion of cities and population growth in recent years has caused an incremental increase of vehicles and heavy traffic, both within cities and in suburban and rural areas. Limited capacity of side walks on the one hand and the daily reduction in the efficiency of main highways on the other, have forced the planners to design u-turns which show a tremendous improvement in highway efficiency for the 12 million population of Tehran. Besides, according to city planning rules and regulations in Iran, the construction of traffic signal crossings are not suggested. 
In a condition of critical management, a powerful earthquake could happen leading to traffic instruments at crossings being destroyed. Vehicles become entrapped in the condensed traffic and there is a constant danger of highway bridges collapsing. In such a critical situation the u-turn can be the best choice to release the traffic pressure.

Afsariyeh highway is one of the most important highways and has a tremendous role in transporting the traffic load from north-east to south and south-east Tehran. At present it posses a saturated traffic volume. In future the occurrence of more condensed traffic volume is expected and it will create a serious effect contributing to an environmental disaster such as air and sound pollution. By constructing a u-turn a part of this load will be released.

\section{Research area description}

In respect of traffic volume, there have been long lines of vehicles and a high rate of yearly car accidents in Afsariyeh highway's main crossing. The first uturn was constructed in 2003 and all traffic lights have been removed. In 2004 a second u-turn was constructed on a second main crossing, which also has a record of many accidents. The plans are shown in Figure 1.

The newly taken satellite picture is in Figure 2, clearly showing the location of the constructed u-turn and the heavy load of traffic in it.

Due to the heavy load of traffic volume, construction of another highway on the east part of the main highway is under study. Therefore, the traffic of heavy vehicles will be prohibited in main highway and besides, that part of the vehicles
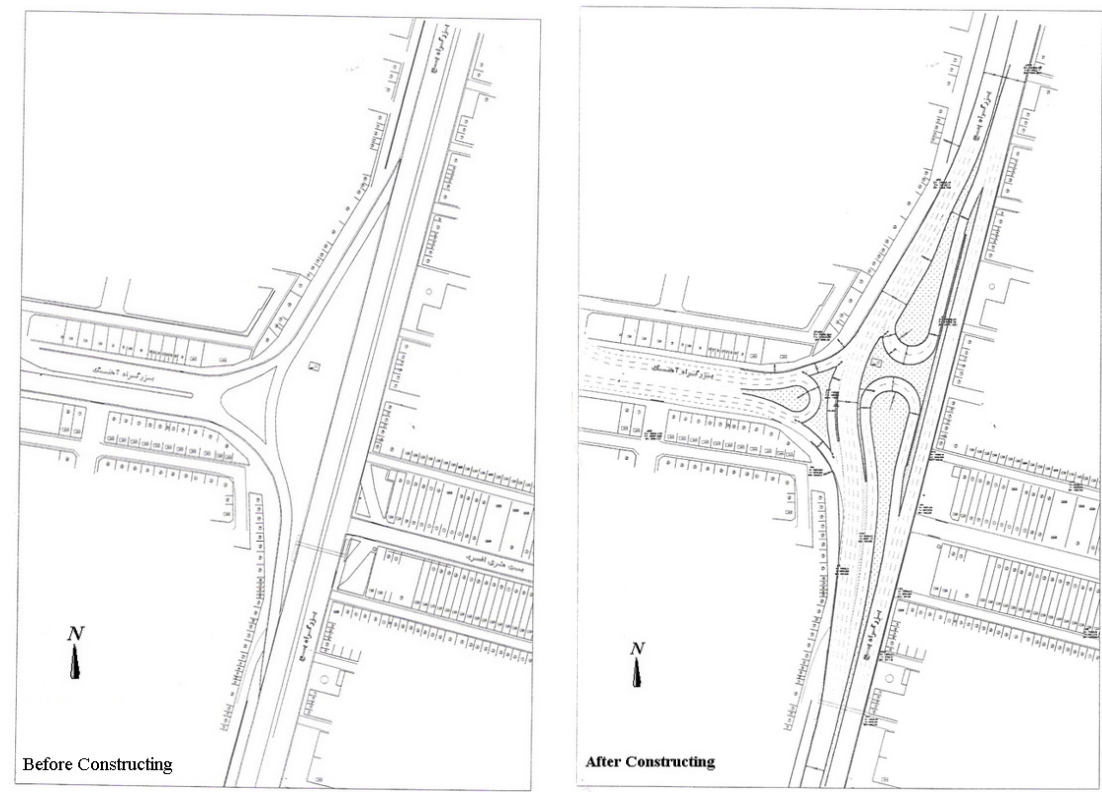

Figure 1: Plan of research area before and after constructing u-turn. 
that are not going to the west part of the city can use the secondary highway simultaneously. This will cause a considerable reduction of traffic volume on the main highway and in such a situation the u-turn will show higher efficiency. Table 1 and Figure 3 show a heavy load of traffic in the main highway.

Table 1: Number of passing vehicles per hour in different years.

\begin{tabular}{|c|c|c|c|c|c|}
\cline { 2 - 6 } \multicolumn{1}{c|}{} & Car & Motor-cycle & Truck & Mini-bus & pcu \\
\hline North-South & 5639 & 226 & 262 & 132 & 6698 \\
\hline South-North & 4827 & 424 & 280 & 120 & 5988 \\
\hline Sum & 10466 & 650 & 542 & 252 & 12686 \\
\hline
\end{tabular}

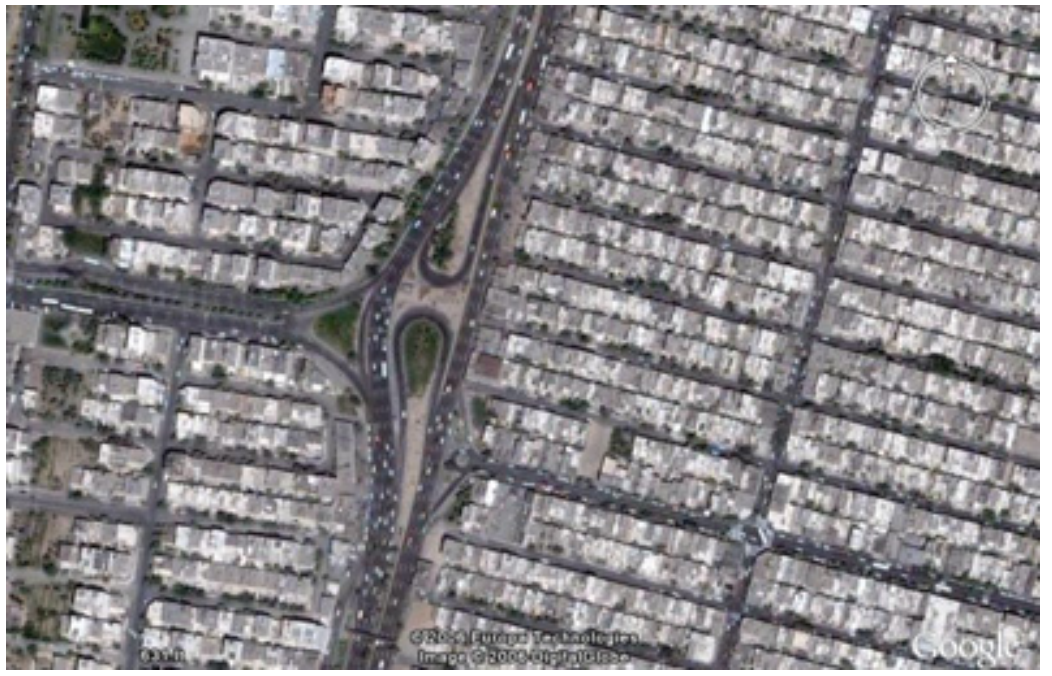

Figure 2: Satellite picture of research area.

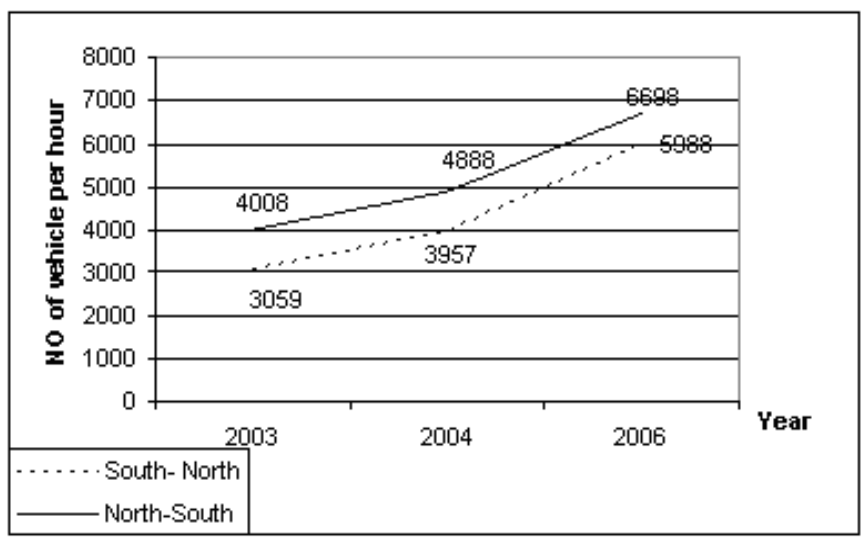

Figure 3: Graphical propaganda of vehicles number per hour in different years. 


\section{Environmental effects of u-turn construction}

Basically the environmental effects of u-turn construction can be divided and analysed in two parts:

\subsection{Sound pollution}

Due to the vibration of a solid mass, liquid and gas sound waves are produced. Basically, that part of any sound which humans find intrusive and are not interested in hearing can be considered as a sound pollution. People who are living close to highways usually suffer from sound pollutions such as:

- Direct effect of sounds on their common psychological system.

- Efficiency reduction in their daily life, unusual tiredness, stress and fatigue.

- Common disorders in their heart beat and digestion system.

- Reduction of their skin resistance against dryness and crack appearance in their skin.

According to present the present study, construction of a u-turn eliminates crossings on highways and causes a tremendous reduction of traffic loads that obviously result in a considerable reduction of sound pollution. Therefore, sound pollution and its side effects on the people living close to the highway is reduced proportionally with the reduction of heavy loads of trapped traffic due to the presence of a u-turn instead of the more conventional crossings.

\subsection{Air pollution}

Due to the activity of vehicles engines, a lot of toxic gas particulate matter spreads into the atmosphere and cause air pollution. Usually the toxic gases consist of No, No2, Nox, Co, Co2, So, So2, Sox and CxHx. Observed particulate matters consist of plumbago and suspended solids. These pollutions cause emphysemas, eye burning and headaches, which in a critical situation it can lead to death.

Experimentally, the ignition of harmful gases discharged from a car has been show in Table 2.

Basically the volume of air pollution due to the activity of vehicles can be calculated by following equation:

$$
\mathrm{V}_{\mathrm{a}}=\mathrm{N} \times \mathrm{a} \times \mathrm{t}
$$


Table 2: Ratio of air pollution in different cases.

\begin{tabular}{|c|c|c|c|}
\hline \multirow{2}{*}{ Engine Condition } & \multicolumn{3}{|c|}{ Component Contain } \\
\cline { 2 - 4 } & $\mathbf{N O}_{\mathbf{x}}$ & $\mathbf{C}_{\mathbf{x}} \mathbf{H}_{\mathbf{x}}$ & $\mathbf{C O}$ \\
\hline Activated but not moving & 1 & 1 & 1 \\
\hline Activation Condition & 100 & 0.4 & 0.6 \\
\hline Moving with Uniform Speed & 66 & 0.3 & 0.6 \\
\hline Speed Reduction & 1 & 11.4 & 0.6 \\
\hline
\end{tabular}

where

$\mathrm{V}_{\mathrm{a}}=$ Volume of air pollution in one hour $\left(\mathrm{m}^{3}\right)$

$\mathrm{N}=$ number of vehicles in one hour

$\mathrm{a}=$ pollution caused by the activity of one vehicle ( $\mathrm{gr} / \mathrm{hr})$

$\mathrm{t}=$ time duration of stopped vehicle (in average the time duration for a stopped vehicle of 0.1 hour or 6 minutes has been assumed)

By using the above mentioned data and formula the following results have been achieved as shown in Figure 4.

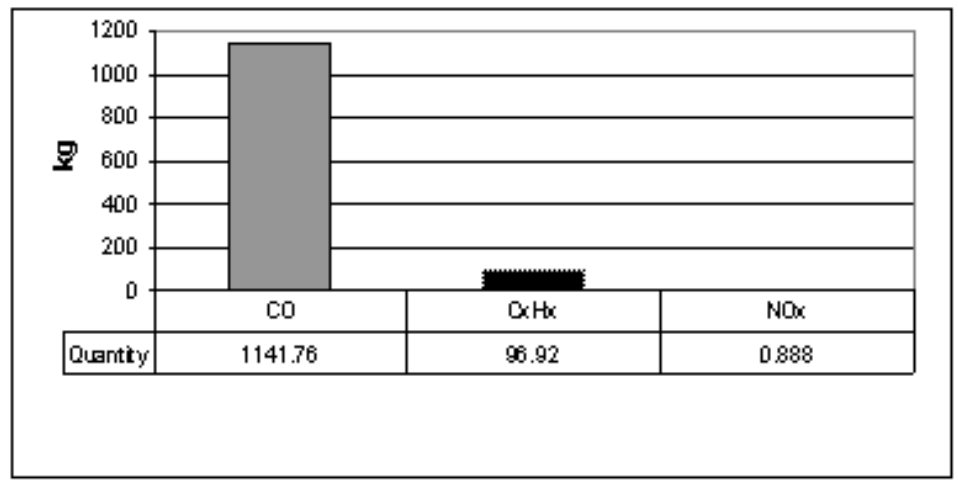

Figure 4: Pollutions produced by incineration of vehicles per hour.

\section{Results and discussions}

Due to our research the following results have been achieved.

\subsection{Positive achievements of u-turn construction in main highway}

- Elimination of traffic lights along the main highway has a positive effect on traffic activity and the psychology of drivers. 
- High improvement on the flow of traffic in the main highway.

- Considerable reduction in traffic cost and time consumption.

- Pollution reduction and environmental situation improvement in the areas around the highway.

- Tremendous improvement in the safety of traffic.

- Average number of accidents at the crossings in highway before u-turn construction was 30 cases per month

- Average number of accidents at the crossings in highway after u-turn construction is equal 3 cases per month, which shows a high reduction of accidents.

- More activated preparation in network of side walks around highway at the time of critical management and occurrences of an earthquake

\subsection{Negative achievements of u-turn construction in main highway}

In Iran construction of u-turns contradict the highway design standards. Therefore it can cause following problems.

- Entrance or exit of vehicles into or out of u-turn in highway.

- Deviation of highway path at the place of u-turn construction.

The particular problem is with the irregular development of Tehran, which has an effect on the standard capability of highways. Therefore, with the construction of u-turns, more capability can be expected in highways. Such capability can be used as a reference to be used at a time of critical management and earthquake occurrence. However, this resolution is not applicable to solve the traffic problem for all crossings on highways. Solutions for resolving such problems can only be made after careful analysis and assessment of each situation separately and choosing the best and most appropriate plan.

\section{Conclusion}

- Before construction of the u-turn in the Afsariyeh highway (east Tehran main highway) all vehicles were forced to stop at the crossings and then they moved after the traffic light turned to green. Therefore, instantaneously vehicles moved to their maximum speed. This type of moving mechanism caused a high level of noise (specially in the case of heavy vehicles) and produced unexpected heavy noise pollution. But 
after u-turn construction and elimination of crossings, vehicles were not forced to stop. They moved with uniform speed and a uniform lower noise load has been achieved respectively. Obviously, a tremendous reduction of noise pollution has been achieved following the u-turn construction.

- At highway crossings, particularly where vehicles are stopped by traffic lights, congestion, or as a result of accidents, the detained time of vehicles can be increased. Therefore, accumulation of air pollution at crossings can be increased respectively. In Tehran the higher accumulation of toxic gas and poisonous solid materials have been observed at crossings in main highways compared to other places. With the elimination of crossings on highways and replacing them with uturn a high amount of air pollution and its dispersion can be eliminated. The considerable reduction of air pollution observed after construction of u-turn is shown in Figure 5.

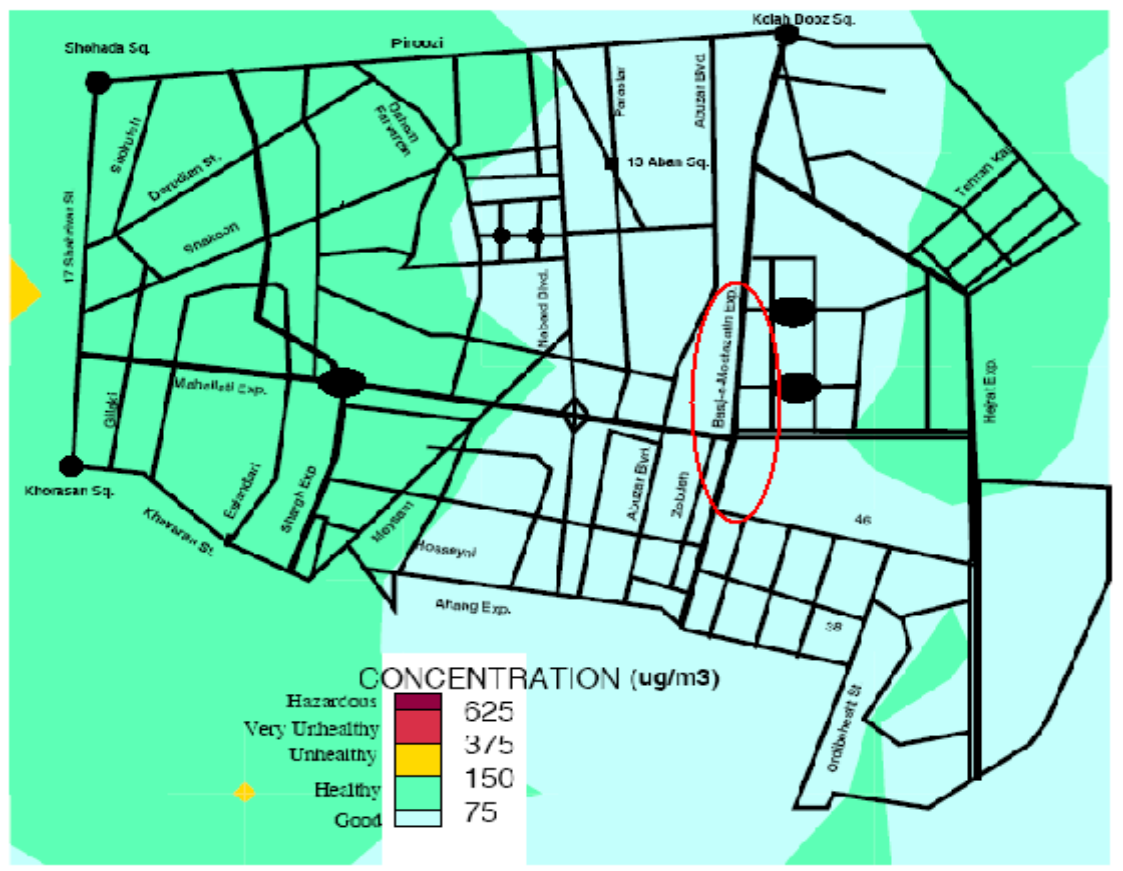

Figure 5: Consideration of air pollution dispersion at highway crossings.

\section{References}

[1] Air quality, Godish thad. Lewis Publisher, 2003.

[2] Air quality Index, United State Environmental Protection Agency, June 2000 . 
[3] B. J. Smith, G. M. Philipps and M. Sweeney, "Environmental Science", Longman London and New York, 1982.

[4] Ben. H. Sharp, Paul R. Donavan, "Motor Vehicle Noise", Chapter 32, Hand book of Noise Control CM. Harris, Second edition McGraw Hill, 1979.

[5] Density of Suspended Particles in East Tehran Air, Report of Air Quality Control company 2003.

[6] Oregon Department of Transportation, January 2000. Guidelines for the Operation of Variable Message Signs on the state High ways.

[7] Sher-E 1998 Hand book of Air pollution from Internal Combustion Engines, Pollutant formation and Control, Boston Academic Press.

[8] Standard Development Plan, Federal Highway Administration US Department of Transportation Washington D.C. June 1996.

[9] The Fatality Effects of Highway Speed Limit by Gender and Age, Thomas S. Dee, Rebecca J. Sela, July 2002. 